\title{
Microstructure evolution during the isostructural decomposition of TiAlN: a combined in-situ small angle x-ray scattering and phase field study
}

Axel Knutsson, Jennifer Ullbrand, Lina Rogström, Niklas Norrby, Lars Johnson, Lars Hultman, J. Almer, M.P. Johansson, B. Jansson and Magnus Odén

\section{Linköping University Post Print}

\section{Tweet}

N.B.: When citing this work, cite the original article.

Original Publication:

Axel Knutsson, Jennifer Ullbrand, Lina Rogström, Niklas Norrby, Lars Johnson, Lars Hultman, J. Almer, M.P. Johansson, B. Jansson and Magnus Odén, Microstructure evolution during the isostructural decomposition of TiAlN: a combined in-situ small angle x-ray scattering and phase field study, 2013, Journal of Applied Physics, (113), 21.

http://dx.doi.org/10.1063/1.4809573

Copyright: American Institute of Physics (AIP)

http://www.aip.org/

Postprint available at: Linköping University Electronic Press http://urn.kb.se/resolve?urn=urn:nbn:se:liu:diva-84702 


\title{
Microstructure evolution during the isostructural decomposition of TiAIN-A combined in-situ small angle $x$-ray scattering and phase field study
}

\author{
A. Knutsson, ${ }^{1}$ J. Ullbrand, ${ }^{1}$ L. Rogström, ${ }^{1}$ N. Norrby,${ }^{1}$ L. J. S. Johnson, ${ }^{2}$ L. Hultman, ${ }^{2}$ \\ J. Almer, ${ }^{3}$ M. P. Johansson Jöesaar, ${ }^{1,4}$ B. Jansson, ${ }^{1,4, a)}$ and M. Odén ${ }^{1, b)}$ \\ ${ }^{1}$ Nanostructured Materials, Department of Physics, Chemistry, and Biology (IFM), Linköping University, \\ Linköping SE-581 83, Sweden \\ ${ }^{2}$ Thin Film Physics Division, Department of Physics, Chemistry, and Biology (IFM), Linköping University, \\ Linköping SE-581 83, Sweden \\ ${ }^{3}$ Advanced Photon Source, Argonne National Laboratory, Argonne, Illinois 60439, USA \\ ${ }^{4}$ Seco Tools AB, SE-73782 Fagersta, Sweden
}

(Received 15 March 2013; accepted 21 May 2013; published online 7 June 2013)

\begin{abstract}
This paper describes details of the spinodal decomposition and coarsening in metastable cubic $\mathrm{Ti}_{0.33} \mathrm{Al}_{0.67} \mathrm{~N}$ and $\mathrm{Ti}_{0.50} \mathrm{Al}_{0.50} \mathrm{~N}$ coatings during isothermal annealing, studied by in-situ small angle $\mathrm{x}$-ray scattering, in combination with phase field simulations. We show that the isostructural decomposition occurs in two stages. During the initial stage, spinodal decomposition, of the $\mathrm{Ti}_{0.50} \mathrm{Al}_{0.50} \mathrm{~N}$ alloy, the phase separation proceeds with a constant compositional wavelength of $\sim 2.8 \mathrm{~nm}$ of the AlN- and TiN-rich domains. The time for spinodal decomposition depends on annealing temperature as well as alloy composition. After the spinodal decomposition, the coherent cubic AlN- and TiN-rich domains coarsen. The coarsening rate is kinetically limited by diffusion, which allowed us to estimate the diffusivity and activation energy of the metals to $1.4 \times 10^{-6} \mathrm{~m}^{2} \mathrm{~s}^{-1}$ and $3.14 \mathrm{eV}^{-1}{ }^{-1}$, respectively. (C) 2013 AIP Publishing LLC. [http://dx.doi.org/10.1063/1.4809573]
\end{abstract}

\section{INTRODUCTION}

Solid solution TiAlN with a cubic (c) crystal structure is one of the most extensively used wear resistant coatings for cutting tool inserts, due to its thermal stability, oxidation resistance, and excellent mechanical properties. $^{1-3}$ It was shown, almost a decade ago, that the alloy is unstable and undergoes two phase transformations. ${ }^{4,5}$ First, it decomposes isostructurally to c-TiN and c-AlN, followed by a transformation of the metastable c-AlN to hexagonal (h)-AlN. The first step has been attributed to spinodal decomposition, since experimental results ${ }^{5-10}$ show the characteristics for this type of phase transformation, and computational methods reveal a miscibility gap and a negative second derivative of the Gibbs' free energy. ${ }^{11-14}$ The mechanical properties of the coatings are improved after the thermal annealing which has been attributed to the isostructural decomposition, due to the resulting coherency strains between the $\mathrm{Al}$ and Ti-rich domains, 5,15 their difference in elastic stiffness, ${ }^{16}$ and also a semi coherent interface between cubic and hexagonal phases. ${ }^{7,10}$ The industrial and scientific interest in the behavior of TiAlN coatings has motivated several studies; $e x$-situ microstructural investigations have been performed after isothermal annealing using, for example, analytical (scanning) transmission electron micrography ((S)TEM), ${ }^{6,17}$ atom probe tomography, ${ }^{18-21}$ and small angle neutron scattering. ${ }^{12}$ These studies confirmed that AlN- and TiN-rich cubic domains evolve during annealing. In-situ annealing experiments have been performed with dynamic heating using differential scanning calorimetry

\footnotetext{
${ }^{\text {a) }}$ Deceased 2012.

b) Author to whom correspondence should be addressed. Electronic mail: magod@ifm.liu.se
}

$(\mathrm{DSC})^{5,6,21,22}$ and small angle $\mathrm{x}$-ray scattering (SAXS), ${ }^{23}$ from which the onset of the decomposition and the involved activation energies were determined. However, the details of the isostructural decomposition are not fully understood, i.e., $\mathrm{c}$-TiAlN $\rightarrow$ c-TiN and c-AlN. The effects of annealing temperature and coating composition on the spinodal decomposition process and the resulting microstructure evolution during this stage are lacking. For example, during decomposition, both theoretical work ${ }^{24-26}$ and experimental studies on polymers ${ }^{27}$ have shown the presence of several decomposition sub-stages, i.e., spinodal decomposition and coarsening. Furthermore, the temperature of the coating at the cutting edge during metal cutting has been reported to increase rapidly, after which a steady state temperature is reached. ${ }^{28}$ The kinetics of the decomposition, resulting from a fast temperature increase followed by isothermal annealing, is thus technically important for the understanding of how the coatings behave during metal cutting. ${ }^{29}$ In this work, arc evaporated $\mathrm{Ti}_{0.50} \mathrm{Al}_{0.50} \mathrm{~N}$ and $\mathrm{Ti}_{0.33} \mathrm{Al}_{0.67} \mathrm{~N}$ coatings were, after a rapid heating, isothermally annealed at 850 and $900^{\circ} \mathrm{C}$ up to $160 \mathrm{~min}$. We show, through a combination of in-situ SAXS measurements and phase field simulations, that the isostructural decomposition occurs in two stages: spinodal decomposition, where a constant wavelength prevails, followed by a second stage where the coherent $\mathrm{AlN}$ - and TiN-enriched domains coarsen.

\section{EXPERIMENTAL DETAILS}

The $\mathrm{Ti}_{1-\mathrm{x}} \mathrm{Al}_{\mathrm{X}} \mathrm{N}$ coatings were deposited using a SulzerMetaplas MZR323 reactive cathodic arc evaporation system operating in pure $\mathrm{N}_{2}$ with a base pressure of $0.5 \mathrm{mPa}$ and a bias of $-20 \mathrm{~V}$. The bias was chosen such that the residual 
stresses in the coatings were reduced to a minimum, but still allowed growth of dense coatings with satisfying substrate adhesion. WC-Co pieces [Seco Tools "HX," chemical composition (wt. \%) WC 93.5-Co 6-(Ta, Nb)C 0.5] were used as substrates. The substrate temperature was approximately $400{ }^{\circ} \mathrm{C}$ during deposition. Before deposition, the substrates were polished to a mirror-like finish and degreased in an ultrasonic cleaning line. The substrates were mounted on a single axis rotating drum facing circular $63 \mathrm{~mm}$ alloyed cathodes of $\mathrm{Ti}_{1-\mathrm{x}} \mathrm{Al}_{\mathrm{x}}$, where $\mathrm{x}=0.67$ and 0.50 for the $\mathrm{Ti}_{0.33} \mathrm{Al}_{0.67} \mathrm{~N}$ and $\mathrm{Ti}_{0.50} \mathrm{Al}_{0.50} \mathrm{~N}$ coatings, respectively. The thicknesses of the coatings were $\sim 8 \mu \mathrm{m}$. The coatings had an actual composition of $\mathrm{x}=0.65$ and $\mathrm{x}=0.47$, for the $\mathrm{x}=0.67$ and $x=0.50$ cathodes, respectively, as measured by energy dispersive $\mathrm{x}$-ray spectroscopy (EDS). In this work, we label them according to the cathode composition. More detailed descriptions of the deposition conditions and compositions of these coating can be found in Ref. 10 .

The scattering experiments were performed at the highenergy synchrotron x-ray beamline 1-ID at the Advanced Photon Source in Illinois, USA, using a photon energy of $65 \mathrm{keV}$, corresponding to a x-ray wavelength of $0.1907 \AA{ }^{30}$ The beam was defined vertically and horizontally to $10 \times 10 \mu \mathrm{m}^{2}$ using slits. An ion chamber in front of the furnace was used to measure incident beam intensity. To reduce the recorded scattered intensity in the close vicinity of the direct beam and thus improving the dynamic range of the SAXS signal, a $\mathrm{Cu}$ conical-shaped attenuator was used in front of the detector. The specimens were sectioned to $1 \mathrm{~mm}$ thick and $5 \mathrm{~mm}$ wide slices, which were mounted in a tungsten sample holder to ensure even heating and a solid fixture. To minimize oxidation of the holder and specimen, they were placed in a closed glass tube allowing a protective flow of $\mathrm{Ar}$ and use of Ti oxidation traps as seen in the schematics of the experimental setup, Figure 1. The heating was performed with infrared radiation from two sides, using a Hi-Temp IR furnace model 5075 from Research, Inc., connected to two Eurotherm temperature controllers. The heating cycle consisted of an initial heating step with a rate of $\sim 110^{\circ} \mathrm{C} / \mathrm{min}$ to the maximum temperatures $\left(\mathrm{T}_{\max }\right), 850$ and $900{ }^{\circ} \mathrm{C}$, and a holding step for 120 and $60 \mathrm{~min}$, respectively. A GE Angio $2048 \times 2048$

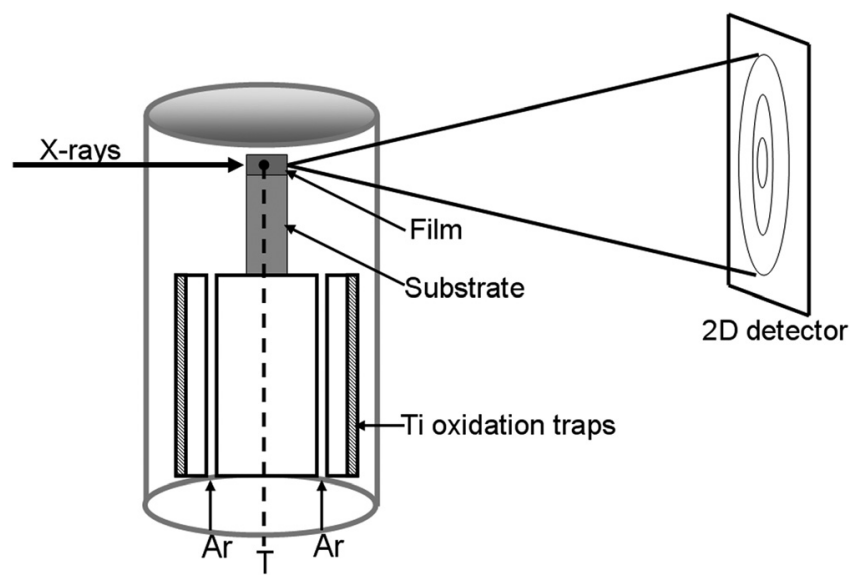

FIG. 1. Schematic drawing of the x-ray scattering setup, showing the substrate with coating inside the glass tube with $\mathrm{T}$ indicating the thermocouple. pixels area detector (pixel size: $200 \times 200 \mu \mathrm{m}^{2}$ ) was placed $1818.1 \mathrm{~mm}$ downstream from the sample to record the scattered intensity. The detector was used both for SAXS and wide-angle X-ray scattering (WAXS) measurements. A detector exposure consisted of five summed two-second snapshots taken continuously during annealing. The read out time between exposures was $\sim 10 \mathrm{~s}$ giving a data sampling rate of $3 \mathrm{~min}^{-1}$. A reference $\mathrm{CeO}_{2}$ powder on the specimen holder was used to calibrate the detector distance and tilt angles. The recorded intensity was corrected for the beam attenuator and detector dark current. Scattering from the furnace and sample holder including the glass tube was subtracted from the data using an exposure without sample. To be able to extract microstructural information from the 2D raw SAXS data images, the data sets were normalized, and transformed into intensity versus reciprocal length (q) graphs. The extraction of a compositional wavelength from these graphs was performed using the software Igor Pro with the Irena package and the maximum entropy method by Jemian, ${ }^{31}$ where a Gaussian function was fitted to the resulting size distribution. The presented wavelengths here are the peak values from the radius size distributions multiplied by four. For more details on the used methods, see Refs. 31-33.

For WAXS analysis, the two dimensional data were transformed to one dimensional patterns using 18 bins of $20^{\circ}$ each. The peak width was extracted by fitting a PseudoVoigt function to the diffraction peak.

The ex-situ microstructural investigation of the postannealed coatings was performed with a combination of TEM and STEM, using a $200 \mathrm{kV}$ FEI Tecnai G ${ }^{2}$ TF 20 UT microscope equipped with an EDS system, allowing for elemental mapping. The STEM analysis was performed with a high angle annular dark field detector with a camera length set to $190 \mathrm{~mm}$. TEM specimens were, because of the limited specimen size, prepared with a focused ion beam (FIB) equipment using a 1540 EsB cross beam instrument from Zeiss. Details of the cross sectional TEM sample preparation by FIB are given in Ref. 34 .

\section{SIMULATIONS}

The microstructural evolution of the coatings was simulated using a continuous phase field approach in two dimensions (2D), with TiAlN approximated as a pseudo-binary system of AIN and TiN. The nitrogen content was set to be homogenous throughout the simulation box. The model only accounts for substitutional diffusion of $\mathrm{Ti}$ and $\mathrm{Al}$ on the metal sublattice. For each node in the simulation box $\left(50 \times 50 \mathrm{~nm}^{2}, 45000\right.$ nodes $)$, the phase field variables are solved for every time step. The temperature was ramped from room temperature with $110^{\circ} \mathrm{C} / \mathrm{min}$ to the maximum temperature $\left(850\right.$ or $\left.900^{\circ} \mathrm{C}\right)$, i.e., the same heating rate and holding temperatures used for the experiments. The driving force for decomposition is the minimization of the system's Gibbs' free energy, $\Delta G$, where the difference compared to the pure $\mathrm{TiN}$ and $\mathrm{AIN}$ is given by

$$
\Delta G=\frac{1}{V_{m}} \int_{\Omega}\left(\Delta G_{m}\left(x_{k}\right)+\kappa\left|\nabla x_{k}\right|^{2}+\Delta E_{e l}\right) d \Omega,
$$


where $V_{m}$ is the molar volume, $\Delta G_{m}$ the molar free energy of mixing, $x_{k}$ the molar fraction of element $k, \kappa$ the gradient energy coefficient, and $\Delta E_{e l}$ is the elastic energy. ${ }^{35}$ The integration is performed over the whole volume, $\Omega$. For a more detailed description of the simulations and the terms in Eq. (1), see Refs. 10, 25, and 35. In this work, values of $\Delta G$ from the unified cluster expansion method by Alling et al. ${ }^{36}$ were used, which predicts some clustering of $\mathrm{Ti}$ and $\mathrm{Al}-$ atoms. An initial atomistic clustering has also been observed in recent studies of as-deposited (a.d.) TiAlN coatings. ${ }^{7,19}$ Here, the entropy of mixing after deposition was assumed to be the same as for the equilibrium situation at $2000 \mathrm{~K}$, the lowest calculated temperature in Ref. 36. The gradient energy coefficient, $\kappa$, was calculated following the procedure out-lined by Cahn and Hilliard, ${ }^{25}$ i.e., the enthalpy of mixing is distributing on the nearest neighbor bonds

$$
\kappa=\frac{\mathrm{b}^{2}}{2} \sum_{\mathrm{i}=0}^{\mathrm{n}}\left(\mathrm{x}_{\mathrm{A}}-\mathrm{x}_{\mathrm{B}}\right)^{\mathrm{i}} \mathrm{L}_{\mathrm{i}},
$$

where $\mathrm{b}$ is the interatomic distance and $L_{n}$ are the coefficients of a Redlich-Kister third order $(n=3)$ polynomial function fitted to the enthalpy of mixing

$$
\Delta H_{m i x}=x_{A} x_{B} \sum_{i=0}^{n}\left(x_{A}-x_{B}\right)^{i} L_{i}
$$

The elastic energy $\Delta E_{e l}$ was calculated following the scheme outlined by Rogström et al. ${ }^{10}$ using the lattice parameters calculated by density functional theory. ${ }^{11}$ The modified Cahn-Hilliard equation, described in Ref. 10, was solved by the software Flex PDE. ${ }^{37}$ The diffusion coefficient, $D_{0}$, for self diffusion and the activation energy, Q, of $\mathrm{Al}$ and $\mathrm{Ti}$ was approximated from the literature to $4.2 \times 10^{-6} \mathrm{~m}^{2} / \mathrm{s}$ and $3.11 \mathrm{eV}^{-1}$, respectively. ${ }^{5,21}$ The wavelength of the compositional fluctuations was extracted by the autocorrelation function, $R(\vec{\tau})$ of the 2D compositional field at every time step

$$
R(\vec{\tau})=\frac{\sum_{\vec{r}}(X(\vec{r})-\bar{X})(X(\vec{r}+\vec{\tau})-\bar{X})}{(N-1) \sigma^{2}},
$$

where $X(\vec{r})$ is an element of the 2D compositional data set in the form of a matrix with dimension $N$, and $\bar{X}$ its mean value and $\sigma$ as its standard deviation; $\vec{\tau}$ and $\vec{r}$ are the position and lag vector, respectively. The radial average of $R(\vec{\tau})$ was calculated, giving the radial autocorrelation function.

\section{RESULTS}

\section{A. Experimental results}

Figure 2(a) shows one dimensional WAXS-lineouts of the $\mathrm{Ti}_{0.33} \mathrm{Al}_{0.67} \mathrm{~N}$ coating in as deposited state and annealed at $920^{\circ} \mathrm{C}$ and $1048^{\circ} \mathrm{C}$. The WAXS diffractograms at as deposited and $920^{\circ} \mathrm{C}$ exclusively show peaks arising from the c-TiAlN phase and the substrate, i.e., for the temperature range where the SAXS measurements were performed. At the higher temperature of $1048^{\circ} \mathrm{C}$, h-AlN is present. Figure 2(b) shows the change in peak width over time of the $\mathrm{Ti}_{0.50} \mathrm{Al}_{0.50} \mathrm{~N}$ coating annealed at $850{ }^{\circ} \mathrm{C}$ and $900{ }^{\circ} \mathrm{C}$. The small decrease in width at $<60 \mathrm{~min}$ is due to stress relaxation and defect annihilation, which are frequently observed during heat treatment of arc evaporated thin films. ${ }^{10}$ At times $>60 \mathrm{~min}$, the peak width is nearly constant with time. Similar lineouts and peak width behavior were obtained for the other annealing temperatures and compositions.

Figure 3 shows SAXS profiles, i.e., scattered intensity versus $q$, of the $\mathrm{Ti}_{0.50} \mathrm{Al}_{0.50} \mathrm{~N}$ coating in its as-deposited state and at $1,20,35$, and $52 \mathrm{~min}$ of the $900{ }^{\circ} \mathrm{C}$ isothermal anneal. The graphs are results of intensity integration over $360^{\circ}$, i.e., a complete SAXS pattern. The seen peaks are results of the scattering from the compositional wavelength. The figure
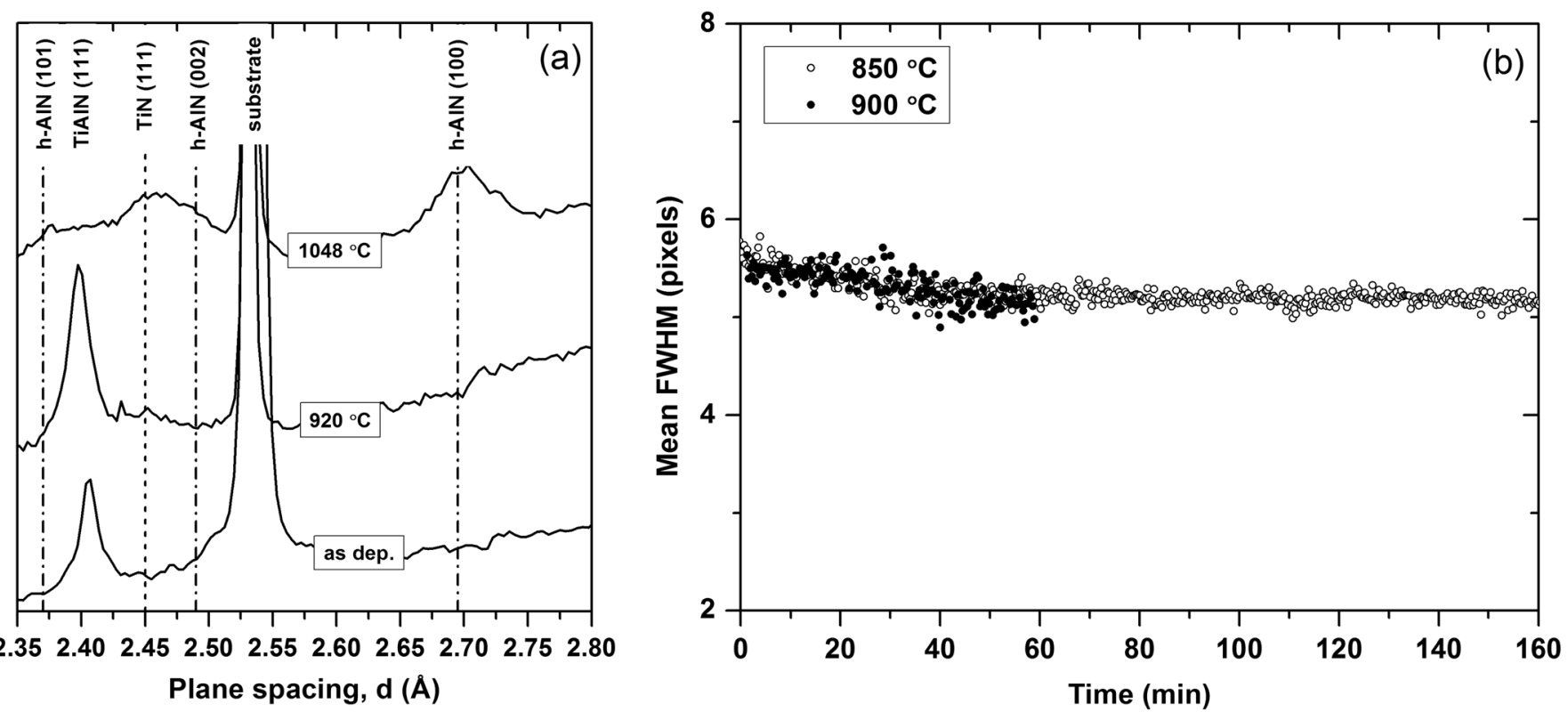

FIG. 2. (a) WAXS lineouts from the $\mathrm{Ti}_{0.50} \mathrm{Al}_{0.50} \mathrm{~N}$ coating after annealing for $1 \mathrm{~h}$ at different temperatures showing no formation of hexagonal AlN below $920^{\circ} \mathrm{C}$, while it has formed at $1048^{\circ} \mathrm{C}$. (b) Shows the peak width with time extracted from the 200 diffraction peak at 850 and $900{ }^{\circ} \mathrm{C}$ annealing. 


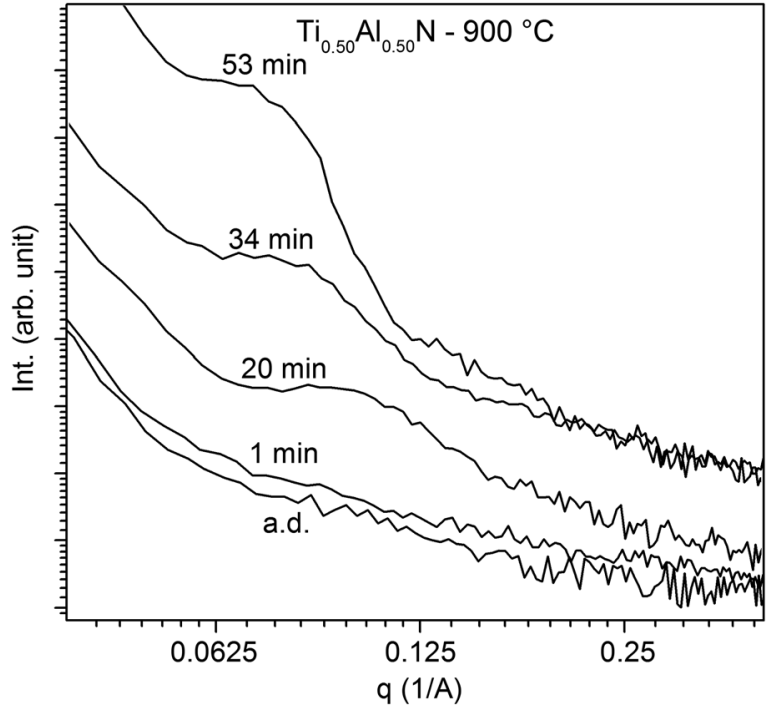

FIG. 3. SAXS profiles of the a.d. $\mathrm{Ti}_{0.50} \mathrm{Al}_{0.50} \mathrm{~N}$ coating and at annealing times of $1,20,35$, and $52 \mathrm{~min}$ at $900^{\circ} \mathrm{C}$.

shows a shift of the peaks toward lower $q$ with increased annealing time, arising from the evolving TiN- and AlN-rich domains. No sign of scattering from the domains is observed from the coating in the as deposited state. Similar profiles were obtained for every detector exposure (time step) for the other annealing temperatures and compositions.

Figure 4 shows the compositional wavelength of the structure extracted from the SAXS profiles versus annealing time, for the $\mathrm{Ti}_{0.50} \mathrm{Al}_{0.50} \mathrm{~N}$ and $\mathrm{Ti}_{0.33} \mathrm{Al}_{0.67} \mathrm{~N}$ coatings annealed at 850 and $900^{\circ} \mathrm{C}$. The $\mathrm{Ti}_{0.33} \mathrm{Al}_{0.67} \mathrm{~N}$ coating has a longer wavelength compared to the $\mathrm{Ti}_{0.50} \mathrm{Al}_{0.50} \mathrm{~N}$ coating throughout both isotherms. For the first minutes of annealing, $\mathrm{t}<20 \mathrm{~min}$ at $850{ }^{\circ} \mathrm{C}$ and $\mathrm{t}<5 \mathrm{~min}$ at $900{ }^{\circ} \mathrm{C}$, the $\mathrm{Ti}_{0.50} \mathrm{Al}_{0.50} \mathrm{~N}$ coating has a constant wavelength $(\sim 2.8 \mathrm{~nm})$ while the $\mathrm{Ti}_{0.33} \mathrm{Al}_{0.67} \mathrm{~N}$ wavelength increases with time. The differences of the wavelength evolution between the two coatings at shorter annealing times are more clearly seen in Figure 7. The increase in

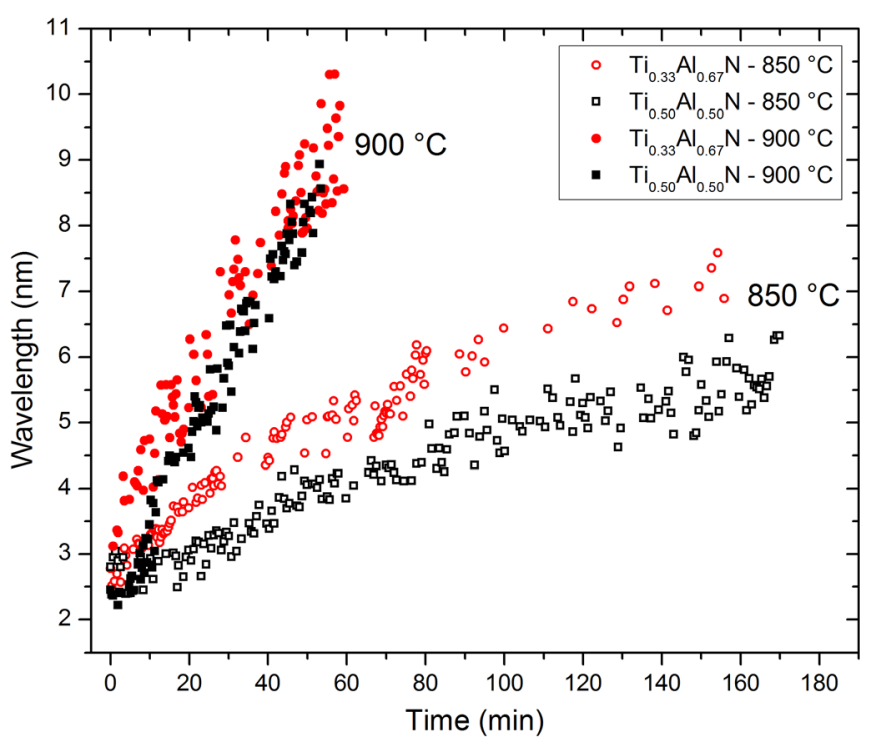

FIG. 4. Extracted wavelength evolution from SAXS data for the $\mathrm{Ti}_{0.50} \mathrm{Al}_{0.50} \mathrm{~N}$ (squares) and $\mathrm{Ti}_{0.33} \mathrm{Al}_{0.67} \mathrm{~N}$ (dots) coatings at $850{ }^{\circ} \mathrm{C}$ (open symbols) and $900^{\circ} \mathrm{C}$ (closed symbols) isothermal annealing. wavelength occurs with similar rates for both compositions for the same annealing temperature. The coatings annealed at $900^{\circ} \mathrm{C}$ have, however, a faster average wavelength evolution of $11.6 \times 10^{-2} \mathrm{~nm} / \mathrm{min}$ compared to $2.8 \times 10^{-2} \mathrm{~nm} / \mathrm{min}$ for the $850{ }^{\circ} \mathrm{C}$ case, i.e., increasing the temperature by $50^{\circ} \mathrm{C}$ causes an increased coarsening rate by a factor of $\sim 4$.

Figure 5 is a STEM (elemental) Z-contrast micrograph of the $\mathrm{Ti}_{0.50} \mathrm{Al}_{0.50} \mathrm{~N}$ coating with an EDS elemental map (inset) after isothermal annealing at $850{ }^{\circ} \mathrm{C}$ for $170 \mathrm{~min}$, i.e., at the maximum time in Figure 4. Similarly to the asdeposited state, ${ }^{10,21}$ the coating exhibits a columnar microstructure. The Z-contrast image and the elemental map (inset) reveal that the originally homogenous distribution of elements has evolved into domains of bright/blue and dark/ red contrast, corresponding to $\mathrm{Ti}$ and Al-rich areas, respectively. The decomposition is present in all columns.

Higher magnification Z-contrast STEM images of the $\mathrm{Ti}_{0.50} \mathrm{Al}_{0.50} \mathrm{~N}$ coatings annealed for (a) $900^{\circ} \mathrm{C}$ for $60 \mathrm{~min}$ and (b) $850{ }^{\circ} \mathrm{C}$ for $170 \mathrm{~min}$, i.e., the state corresponding to the end points in the plots in Figure 4, are given in Figure 6. Similar structures were observed for the $\mathrm{Ti}_{0.33} \mathrm{Al}_{0.67} \mathrm{~N}$ coating (not shown). The decomposed structure, after annealing at $900{ }^{\circ} \mathrm{C}$, has larger domains compared to the $850^{\circ} \mathrm{C}$ case. The lattice resolved high resolution TEM (HRTEM) image in Fig. 6(c) indicates a coherent cubic lattice across the decomposed areas. Similar structures, with coherent domains, were observed in the other three coatings in their final post annealed states, which is consistent with the WAXS-data showing a cubic structure, with no evidence for h-AlN formation during these heat treatments. Apparently, the coarsening has not proceeded long enough to trigger the transformation to h-AlN.

Table I gives the compositional wavelength in the STEM images (Figures 6(a) and 6(b)) of the two compositions and two annealing temperatures using the autocorrelation function, as described in Sec. III. The extracted wavelength are

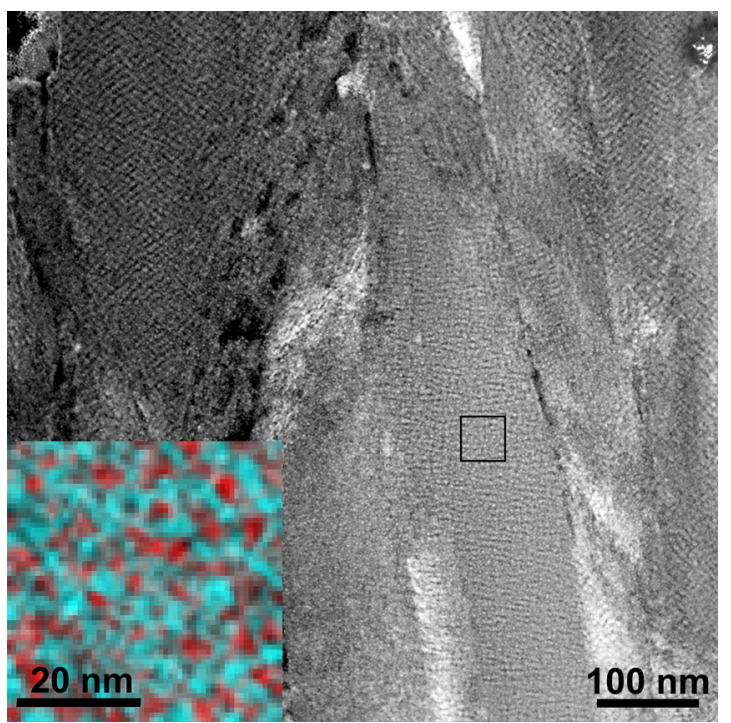

FIG. 5. An overview HAADF STEM micrograph of the $\mathrm{Ti}_{0.50} \mathrm{Al}_{0.50} \mathrm{~N}$ coating after isothermal annealing for $120 \mathrm{~min}$ at $850^{\circ} \mathrm{C}$. The inserted EDS elemental map, where blue represents $\mathrm{Ti}$ and red $\mathrm{Al}$, corresponds to the $50 \times 50 \mathrm{~nm}^{2}$ box. 


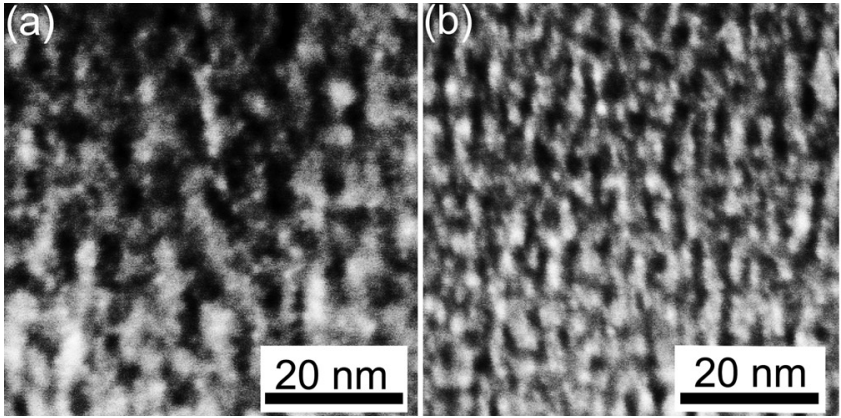

comparable with the ones from the same times and temperatures extracted with the SAXS technique, which are presented within parentheses in the table.

\section{B. Simulation results}

Figure 7 plots the compositional wavelengths over time for $\mathrm{Ti}_{0.50} \mathrm{Al}_{0.50} \mathrm{~N}$ and $\mathrm{Ti}_{0.33} \mathrm{Al}_{0.67} \mathrm{~N}$ at 850 and $900{ }^{\circ} \mathrm{C}$ from the phase field simulations. The experimentally determined wavelengths of the domains from Figure 4, at 850 and $900{ }^{\circ} \mathrm{C}$ up to 50 and $25 \mathrm{~min}$, respectively, are also inserted in the figure for comparison. Both the experimental and simulated data start from the moment the set temperature is reached. The decomposition, for all compositions and temperatures, initially results in a plateau, i.e., a period of time where the wavelength does not change with time. The plateau wavelength increases slightly from 2.36 to $2.40 \mathrm{~nm}$ for $\mathrm{Ti}_{0.33} \mathrm{Al}_{0.67} \mathrm{~N}$ and from 2.88 to $2.96 \mathrm{~nm}$ for $\mathrm{Ti}_{0.50} \mathrm{Al}_{0.50} \mathrm{~N}$ when increasing the temperature from $850^{\circ} \mathrm{C}$ to $900{ }^{\circ} \mathrm{C}$. The duration of the plateau is shorter for $\mathrm{Ti}_{0.33} \mathrm{Al}_{0.67} \mathrm{~N}$ than for $\mathrm{Ti}_{0.50} \mathrm{Al}_{0.50} \mathrm{~N}$, with a length of $2.6 \mathrm{~min}$ compared to $5.7 \mathrm{~min}$ in the $850^{\circ} \mathrm{C}$ case, and $0.07 \mathrm{~min}$ compared to $1.2 \mathrm{~min}$ at $900^{\circ} \mathrm{C}$. At the end of the plateau, a small dip is observed, after which an increase of the wavelength is seen for both compositions. Following the plateau, the growth is initially faster for the $\mathrm{Ti}_{0.33} \mathrm{Al}_{0.67} \mathrm{~N}$ coating. For longer times $(>5 \mathrm{~min})$, the coarsening rate of $\mathrm{Ti}_{0.33} \mathrm{Al}_{0.67} \mathrm{~N}$ is decreased resulting in the same rate for the two compositions at a given temperature.

Figure 8 gives the simulated microstructure evolution of $\mathrm{Ti}_{0.33} \mathrm{Al}_{0.67} \mathrm{~N}$ annealed at $850{ }^{\circ} \mathrm{C}$ for (a) 1.5 , (b) 2.6 , (c) $25 \mathrm{~min}$, and (d) at $900{ }^{\circ} \mathrm{C}$ for $25 \mathrm{~min}$, all viewed in the [001]direction, with red corresponding to $\mathrm{Al}$ and blue to $\mathrm{Ti}$. The microstructural images correspond to the two observed stages in the wavelength evolution in Figure 7, where the times and temperatures of the simulated images are marked with arrows. During the first stage, Figure 8(a), the microstructure evolves in elongated domains in random directions.

TABLE I. Compositional wavelength $(\lambda)$ extracted by the autocorrelation function from STEM images, Figures 6(a) and 6(b), of the $\mathrm{Ti}_{0.33} \mathrm{Al}_{0.67} \mathrm{~N}$ and $\mathrm{Ti}_{0.50} \mathrm{Al}_{0.50} \mathrm{~N}$ coatings annealed at 850 and $900^{\circ} \mathrm{C}$. The data in parentheses represent the wavelength extracted from the SAXS at the same temperatures and times (from Figure 4).

\begin{tabular}{lcc}
\hline \hline Temperature $\left({ }^{\circ} \mathrm{C}\right)$ & $\lambda(\mathrm{nm}) \mathrm{Ti}_{0.33} \mathrm{Al}_{0.67} \mathrm{~N}$ & $\lambda(\mathrm{nm}) \mathrm{Ti}_{0.50} \mathrm{Al}_{0.50} \mathrm{~N}$ \\
\hline $850(170 \mathrm{~min})$ & $7.6(7.2)$ & $5.6(5.9)$ \\
$900(60 \mathrm{~min})$ & $10.4(10.1)$ & $8.4(8.3)$ \\
\hline \hline
\end{tabular}

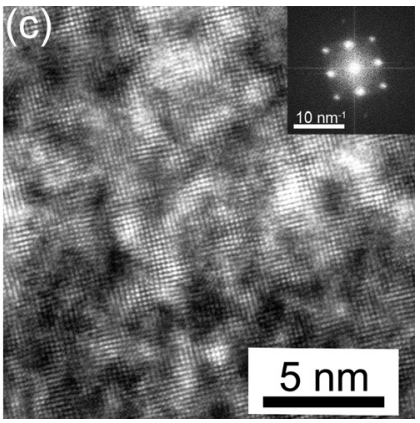

FIG. 6. STEM micrographs of the $\mathrm{Ti}_{0.50}$ $\mathrm{Al}_{0.50} \mathrm{~N}$ coating annealed for (a) $60 \mathrm{~min}$ at $900{ }^{\circ} \mathrm{C}$ and for (b) $120 \mathrm{~min}$ at $850^{\circ} \mathrm{C}$. Image (c) shows a high resolution TEM micrograph of (a)

At the end of this stage, circular domains evolve inside the Al-rich elongated domains as seen in Figure 8(b). In the second stage, Figures $8(\mathrm{c})$ and $8(\mathrm{~d})$, at $\mathrm{t}>2.6 \mathrm{~min}\left(850^{\circ} \mathrm{C}\right)$ and $\mathrm{t}>1.5 \mathrm{~min}\left(900^{\circ} \mathrm{C}\right)$ the domains coarsen. The images further show that the domains grow faster at $900{ }^{\circ} \mathrm{C}$ compared to $850^{\circ} \mathrm{C}$. The corresponding times and temperatures of the simulated images are marked with arrows in Figure 7.

\section{DISCUSSION}

The STEM image and the elemental map in Figure 5 show that the coatings decompose to AlN- and TiN-rich domains during isothermal annealing. The corresponding lattice resolved image, Figure 6(c), reveals isostructural coherent domains. This is what can be expected from spinodal decomposition and is in accordance with earlier observations. $^{4,6,38}$ Even if some inaccuracy related to projection errors from overlapping domains is expected in the wavelength determinations from the STEM images, they agree well with the wavelength extracted from the SAXS measurements for all compositions and temperatures (see Table I). They are also comparable with earlier published compositional wavelengths of decomposed $\mathrm{Ti}_{1-\mathrm{x}} \mathrm{Al}_{\mathrm{X}} \mathrm{N}$, when taking into account the annealing temperatures, times, and heating

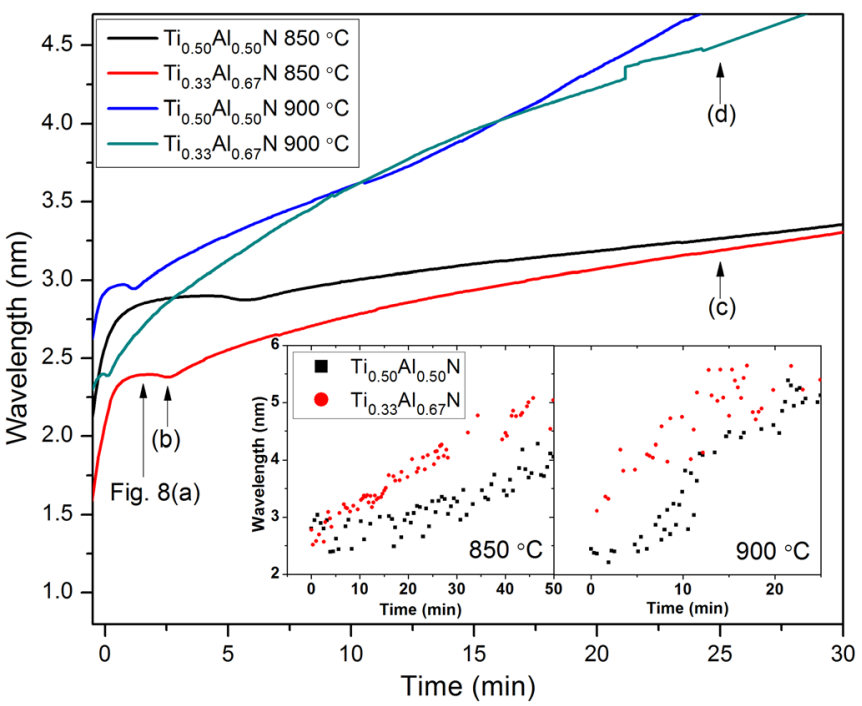

FIG. 7. Simulated compositional wavelength versus annealing time of $\mathrm{Ti}_{0.33} \mathrm{Al}_{0.67} \mathrm{~N}$ and $\mathrm{Ti}_{0.50} \mathrm{Al}_{0.50} \mathrm{~N}$ at 850 and $900^{\circ} \mathrm{C}$. Time equal 0 is set at the time when the simulation reaches the maximum annealing temperature. Insets show SAXS-wavelength data from annealing at $850^{\circ} \mathrm{C}$ (left) and $900{ }^{\circ} \mathrm{C}$ (right). The arrows in the figure indicate the times for the simulated microstructure shown in Figures 8(a)-8(d). 


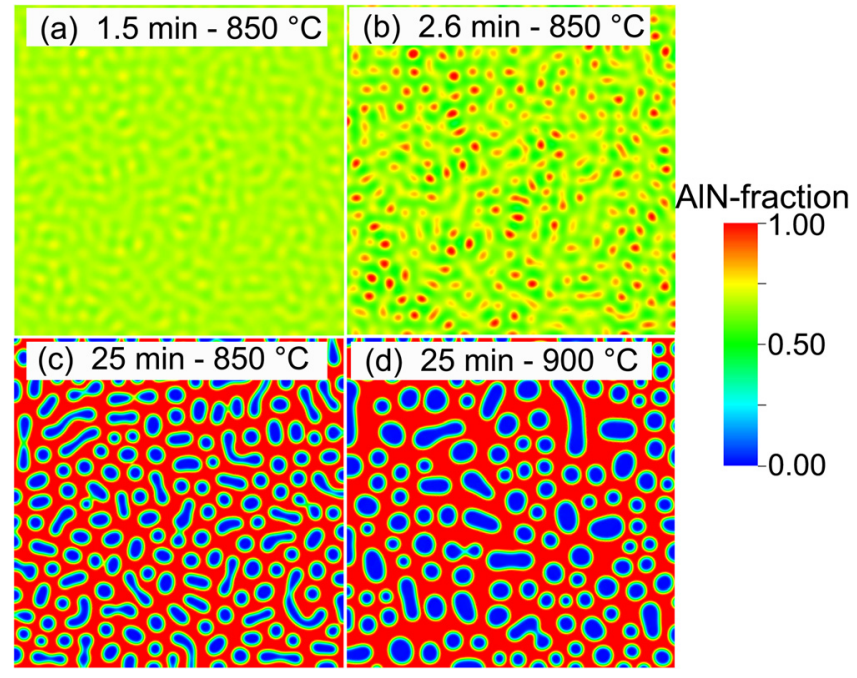

FIG. 8. Simulated microstructure evolution of $\mathrm{Ti}_{0.33} \mathrm{Al}_{0.67} \mathrm{~N}\left(50 \times 50 \mathrm{~nm}^{2}\right.$ sized box), with red representing AlN and blue TiN seen in the [001] direction, after annealing at $850{ }^{\circ} \mathrm{C}$ for (a) $1.5 \mathrm{~min}$, (b) $2.6 \mathrm{~min}$ and (c) $25 \mathrm{~min}$ and at (d) $900^{\circ} \mathrm{C}$ for $25 \mathrm{~min}$.

rate. ${ }^{6-8,12,19}$ Based on these agreements, we conclude that the in-situ measured wavelength extracted from the 2DSAXS patterns, as seen in Figure 4, is trustworthy. Both the experimental results and the simulations show two stages in the isostructural decomposition, one stage with constant wavelength over time (plateau) followed by a stage of coarsening. In the simulations, an additional dip is seen in the end of the plateaus, which is a result of formation of circular domains in the previously elongated microstructure, as seen Figure $8(\mathrm{~b})$. It results in a decrease of the average simulated wavelength extracted by the autocorrelation function, and it is not resolved in the SAXS experiments. Here, we accordingly discuss the isostructural decomposition over time in two stages, the initial stage (spinodal decomposition) and the latter stage (coarsening).

\section{A. Initial stage (spinodal decomposition)}

The lack of a distinct SAXS peak from the as deposited coatings suggests that the coating is largely homogenous or that there is no common compositional wavelength. Randomly distributed minute inhomogeneities have, however, recently been observed in as deposited $c-\mathrm{Ti}_{1-\mathrm{x}} \mathrm{Al}_{\mathrm{x}} \mathrm{N}$ coatings with the more sensitive atom probe tomography technique. ${ }^{7,19}$ However, these inhomogeneities are on an intensity scale lower than what could be resolved with the used SAXS set up or by WAXS in earlier publications. ${ }^{4,5,7,9,10,17,22,39}$ Figure 3 shows that when the annealing temperature is reached a SAXS peak is immediately present. This suggests that the spinodal decomposition starts instantaneously at, or even before, the annealing temperature is attained. The presence of the SAXS peak in combination with no observed WAXS peak broadening indicates that SAXS is a suitable technique to resolve the initial stage of spinodal decomposition. This is in line with the observations in the work by Rachbauer et al. ${ }^{7}$ where no peak broadening in the diffractograms is reported after annealing at $900{ }^{\circ} \mathrm{C}$ for $1 \mathrm{~min}$, even though the atom probe tomography results show increasing compositional amplitude and the formation of TiN- and AlN-enriched domains. It is also consistent with observations made earlier by Rogström et al. ${ }^{10}$ on similar coatings, where a pronounced broadening was not seen until $1000{ }^{\circ} \mathrm{C}$, c.f. Figure 2. Furthermore, it is in accord with published in-situ DSC thermograms of the coatings, where the peak corresponding to the spinodal decomposition has an onset at $\sim 800-850{ }^{\circ} \mathrm{C} .^{4,6}$ The early onset of the decomposition is confirmed in the simulation, where it has already started when the annealing temperature is reached, despite excluding the promotional effects from internal interfaces. ${ }^{40}$

During the first stage of spinodal decomposition, the phase separation proceeds with a constant compositional wavelength. ${ }^{24} \mathrm{~A}$ constant wavelength with annealing time is also what the simulations yield, see Figure 7 . We therefore conclude that what the experiments show as a constant wavelength is the initial stage of the isostructural decomposition. The amplitude of the compositional modulations at this stage is expected to grow exponentially with time, ${ }^{24,25}$ as seen in Figures 8(a) and 8(b). This should result in an increase of the SAXS peak intensity because of the higher contrast of electron density as a result of separation of $\mathrm{Al}$ and $\mathrm{Ti}^{41}$ These changes in intensity are not sufficient to be resolved in the experimental setup, as thermal drift of the specimens during annealing causes the irradiated sample volume to vary over time. The plateau, i.e., the constant wavelength with time, gives the wavelength with the fastest growing amplitude, which depends on the gradient energy and its ratio to the second derivative of Gibbs' free energy. As seen in Figure 7, there is a good agreement between the $\mathrm{Ti}_{0.50} \mathrm{Al}_{0.50} \mathrm{~N}$ coatings' simulated and experimental wavelengths at the plateau, all found to be within a range of $\sim 0.5 \mathrm{~nm}$. The plateau wavelength $\left(\lambda_{\text {plateau }}\right)$ is according to the theory of Cahn, $\sqrt{2}$ times the critical wavelength $\left(\lambda_{\text {crit }}\right)^{42}$ which can be calculated as

$$
\lambda_{\text {crit }}=2 \pi \sqrt{\frac{-2 \kappa}{\frac{\partial^{2} G\left(G_{m}, \kappa\right)}{\partial x_{k}^{2}}}} .
$$

For $\mathrm{Ti}_{0.33} \mathrm{Al}_{0.67} \mathrm{~N}, \lambda_{\text {plateau }}=\sqrt{2} \lambda_{\text {crit }}$ is at 850 and $900{ }^{\circ} \mathrm{C}$ equal to $2.04 \mathrm{~nm}$ and $2.03 \mathrm{~nm}$, respectively, and $2.44 \mathrm{~nm}$ and $2.45 \mathrm{~nm}$ for $\mathrm{Ti}_{0.50} \mathrm{Al}_{0.50} \mathrm{~N}$, as calculated by Eq. (5) using thermodynamic data from Alling et al. ${ }^{11}$ These values are smaller than the plateau wavelength of the simulated data, which are $2.39 \mathrm{~nm}$ and $2.40 \mathrm{~nm}$ at 850 and $900{ }^{\circ} \mathrm{C}$ for $\mathrm{Ti}_{0.33} \mathrm{Al}_{0.67} \mathrm{~N}$, respectively, and $2.88 \mathrm{~nm}$ and $2.96 \mathrm{~nm}$ for $\mathrm{Ti}_{0.50} \mathrm{Al}_{0.50} \mathrm{~N}$. The difference stems from how the two methods handle the elastic properties of the material. Equation (5) does not take into account the effect from the compositional dependent elastic properties, ${ }^{8}$ while it is a contributing factor in the simulations. Furthermore, the autocorrelation extracts the average wavelength while Eq. (5) calculates the smallest existing one. However, the same trends are seen when the temperature and composition are altered, i.e., larger plateau wavelength of the $\mathrm{Ti}_{0.50} \mathrm{Al}_{0.50} \mathrm{~N}$ compared to the $\mathrm{Ti}_{0.33} \mathrm{Al}_{0.67} \mathrm{~N}$, and very small differences $(<0.2 \mathrm{~nm})$ with temperature. These results, in combination with the agreement between simulated and experimental plateau wavelengths, confirm the power of the 
simulation model to predict the thermodynamic behavior of $\mathrm{Ti}_{1-x} \mathrm{Al}_{\mathrm{x}} \mathrm{N}$. Figure 7 further shows that the decomposing $\mathrm{Ti}_{0.33} \mathrm{Al}_{0.67} \mathrm{~N}$ exhibits a plateau time, which is shorter (simulated), or even not resolved (experimental), compared to the $\mathrm{Ti}_{0.50} \mathrm{Al}_{0.50} \mathrm{~N}$. This means that the initial stage of the decomposition tends to be shorter in time for the coating with higher $\mathrm{Al}$ content, at the same temperature. The faster decomposition is a consequence of the asymmetric miscibility gap, which results in a higher driving force for decomposition in the $\mathrm{Ti}_{0.33} \mathrm{Al}_{0.67} \mathrm{~N}$ coating. ${ }^{36}$ The even shorter plateau time in the experimental case can be addressed to slightly incorrect diffusivities or driving forces in the simulations, or microstructural effects not considered in the simulations, such as growth induced defects, and a different degree of compositional fluctuations in the as deposited films. A high lattice defect (vacancies and interstitials) concentration is expected in these coatings due the cathodic arc evaporation process ${ }^{43,44}$ which we believe promotes the spinodal decomposition rate because of the improved conditions for diffusion. The high heating rate and short annealing times cause such defects to still be present during decomposition. This may consequently result in shorter plateau times in the experiments compared to the simulated results.

The duration of the plateau decreases when the temperature is increased from 850 to $900^{\circ} \mathrm{C}$ by a factor of $1 / 4$. This is seen both in the simulations and experimental results, and is due to the temperature dependency of the diffusion. This demonstrates that the initial stage is affected both by diffusion and the composition, i.e., the driving force given by Gibbs' free energy. The results suggest that a $\mathrm{Ti}_{1-x} \mathrm{Al}_{\mathrm{x}} \mathrm{N}$ coating annealed at $900^{\circ} \mathrm{C}$ for $5 \mathrm{~min}$, or even shorter times depending on the composition, can be in a late decomposed state.

\section{B. Latter stage (coarsening)}

The latter stage of the decomposition is driven by the minimization of the gradient (or interface) energy of the system, and is limited by diffusion. This results in a lower number of domains when the small domains coarsen. ${ }^{24}$ In the experimental results, this stage is expressed as a shift of the SAXS-peak towards a smaller scattering vector q over time as seen in Figure 3 and, consequently, a wavelength that increases with time in Figure 4. Such peak shift has been observed in several other material systems that undergo spinodal decomposition, and is reported to be a result of domain coarsening. ${ }^{26,27,41}$ The domain coarsening is here observed in both the experimental and simulated results. The simulations show an initially slightly faster coarsening rate for the $\mathrm{Ti}_{0.33} \mathrm{Al}_{0.67} \mathrm{~N}$ compared to $\mathrm{Ti}_{0.50} \mathrm{Al}_{0.50} \mathrm{~N}$, as seen in Figure 7 . Even though the energy cost for a gradient in $\mathrm{Ti}_{0.33} \mathrm{Al}_{0.67} \mathrm{~N}$ is lower, the higher number of gradients due to its smaller $\sqrt{2} \lambda_{\text {crit }}$ will result in a higher total gradient energy, and thus a faster initial coarsening rate compared to the $\mathrm{Ti}_{0.50} \mathrm{Al}_{0.50} \mathrm{~N}$. The initially faster coarsening rate of the $\mathrm{Ti}_{0.33} \mathrm{Al}_{0.67} \mathrm{~N}$ is also a result of its slightly lower elastic energy stored during the decomposition compared to $\mathrm{Ti}_{0.50} \mathrm{Al}_{0.50} \mathrm{~N}$. For any given temperature, the two energies will reach a steady state expressed, as similar coarsening rates for the two compositions as seen in Figure 7. This occurs when the two compositions have the same wavelength. Hence, due to the coinciding driving forces for the two compositions, it is likely that diffusion is the limiting factor during coarsening of decomposed $\mathrm{Ti}_{1-x} \mathrm{Al}_{\mathrm{x}} \mathrm{N}$. Based on the agreements between late experimental and simulated coarsening rates, showing approximately the same rate for the two compositions at the same temperature, we accordingly suggest that the coarsening is primarily controlled by diffusion and is independent of composition. The coarsening rate increases with increasing temperature since the diffusion rate is increased. This effect is seen both experimentally and in the simulations.

At an even more evolved stage then what was recorded in this study, the c-AlN domains have grown large enough to transform to h-AlN. This transformation is strongly affected by the pressure and the coherency strain between TiN and AlN. ${ }^{45}$

\section{Diffusivity constant and activation energy}

If one assumes that the diffusivities for the two compositions are approximately similar, which according to our experimentally measured coarsening rates is reasonable, it is possible to calculate a diffusivity constant $\left(D_{0}\right)$ and an activation energy $(Q)$. Based on the experimental coarsening rates, suggesting that the diffusivity at $900^{\circ} \mathrm{C}\left(D_{900}^{\exp } \mathrm{C}\right)$ appears to increase approximately with a factor four $(\mathrm{m})$ compared to at $850^{\circ} \mathrm{C}\left(D_{850^{\circ} \mathrm{C}}^{\exp }\right)$, gives

$$
D_{900^{\circ} \mathrm{C}}^{\exp }=m \cdot D_{850^{\circ} \mathrm{C}}^{\exp } \text {. }
$$

By using a Arrhenius type equation to describe the diffusivity at the two temperatures $\left(\mathrm{T}_{1}=850^{\circ} \mathrm{C}\right.$ and $\left.\mathrm{T}_{1}=900^{\circ} \mathrm{C}\right)$ as

$$
\begin{aligned}
& D_{850^{\circ} \mathrm{C}}^{\exp }=D_{0} e^{\left(-\frac{Q}{R T_{1}}\right)}, \\
& D_{900^{\circ} \mathrm{C}}^{\exp }=D_{0} e^{\left(-\frac{Q}{R T_{2}}\right)},
\end{aligned}
$$

where $R$ is the gas constant and $T$ the temperature, $Q$ can be solved together with Eq. (6) to

$$
Q=R \cdot \ln (m)\left(\frac{T_{2}-T_{1}}{T_{1} T_{2}}\right),
$$

which results in a calculated $Q$ of $3.14 \mathrm{eV}^{-1}$. By the same mathematical procedure, but instead utilizing the factor $(n)$ between the experimental $\left(D^{\exp }\right)$ and the known set diffusivity used in the simulations $\left(D^{\operatorname{sim}}\right)$, the diffusivity constant from the experiments will be given as

$$
D_{0}=n_{T_{1}} \cdot \frac{D^{s i m}}{e^{\left(-\frac{Q}{R T_{1}}\right)}}=n_{T_{2}} \cdot \frac{D^{s i m}}{e^{\left(-\frac{Q}{R T_{2}}\right)}} .
$$

Hence, by using the previously extracted value of $Q$ in Eq. (9), the $D_{0}$ is calculated to $1.4 \times 10^{-6} \mathrm{~m}^{2} \mathrm{~s}^{-1}$. The extracted activation energy can be compared with the ones previously measured with DSC for similar coatings; $2.9 \mathrm{eV}$ (Ref. 21) and $3.4 \mathrm{eV} .{ }^{5}$ We note that our calculated $Q$ is of the same magnitude. $D_{0}$ does not offer the same straight-forward 
comparison with previously published data due to its dependence on, e.g., vacancy concentration. $\mathrm{D}_{0}$ will therefore vary strongly depending on synthesis conditions and type of diffusion, i.e., self diffusion or grain boundary diffusion. ${ }^{46}$

Studies have shown that the spinodal decomposition and the coarsening can be concurrent processes for other material systems, ${ }^{26,27}$ and thus care has to be taken when separating the two stages. Here, both simulations and experimental results indicate that it is possible to resolve the two stages in an arc evaporated $\mathrm{Ti}_{0.50} \mathrm{Al}_{0.50} \mathrm{~N}$ coating. From an application point of view, these findings suggest that after a short time of metal cutting, considering that the temperatures may reach above $900{ }^{\circ} \mathrm{C},{ }^{28}$ the coating is in the coarsening stage.

\section{CONCLUSIONS}

Our study on the influence of composition and temperature on the kinetics of the isostructural decomposition of unstable $\mathrm{c}-\mathrm{Ti}_{1-\mathrm{x}} \mathrm{Al}_{\mathrm{x}} \mathrm{N}$ coatings, by small angle $\mathrm{x}$-ray scattering and phase-field simulations, shows that it has two stages. During the initial stage, spinodal decomposition, the compositional wavelength is constant with annealing time. This stage is shorter in time for the higher $\mathrm{Al}$ content coating due to the asymmetric miscibility gap, which results in a larger driving force for decomposition. In the second stage, the AlN- and TiN-rich domains coarsen with a rate that is independent of composition and limited by diffusion. The higher annealing temperature $\left(900{ }^{\circ} \mathrm{C}\right)$ results in both a shorter initial stage of decomposition as well as a higher coarsening rate compared to the lower temperature $\left(850^{\circ} \mathrm{C}\right)$, which is what can be expected for a diffusion driven process. By combining the experimental and simulated results, the activation energy of the metal diffusion was calculated to be $3.14 \mathrm{eV} \mathrm{at}^{-1}$.

\section{ACKNOWLEDGMENTS}

This work was supported by the SSF project Designed Multicomponent Coatings, MultiFilms, the Swedish Research Council (VR), and the VINNEX Center of Excellence on Functional Nanoscale Materials (FunMat). The use of the Advanced Photon Source was supported by the U. S. Department of Energy, Office of Science, Office of Basic Energy Sciences under Contract No. DE-AC02-06CH11357.

${ }^{1}$ H. A. Jehn, S. Hofmann, V.-E. Rückborn, and W.-D. Münz, J. Vac. Technol. A 4, 2701 (1986).

${ }^{2}$ O. Knotek, W. D. Mûnz, and T. Leyendecker, J. Vac. Technol. A 5, 2173 (1987).

${ }^{3}$ G. Beensh-Marchwicka, L. Krol-Stepniewska, and W. Posadowski, Thin Solid Films 85(3-4), 299 (1981).

${ }^{4}$ A. Hörling, L. Hultman, M. Odén, J. Sjölén, and L. Karlsson, J. Vac. Technol. A 20, 1815 (2002).

${ }^{5}$ P. H. Mayrhofer, A. Hörling, L. Karlsson, J. Sjölén, C. Mitterer, and L. Hultman, Appl. Phys. Lett. 83(10), 2049 (2003).

${ }^{6}$ A. Knutsson, M. P. Johansson, P. O. A. Persson, L. Hultman, and M. Odén, Appl. Phys. Lett. 93, 143110 (2008).
${ }^{7}$ R. Rachbauer, S. Massi, E. Stergar, D. Holec, D. Kiener, J. Keckes, J. Patscheider, M. Stiefel, H. Leitner, and P. H. Mayrhofer, J. Appl. Phys. 110, 023515 (2011).

${ }^{8}$ N. Norrby, M. P. Johansson, R. M'Saoubi, and M. Odén, Surf. Coat. Technol. 209, 203 (2012).

${ }^{9}$ A. E. Santana, A. Karimi, V. H. Derflinger, and A. Schütze, Tribol. Lett. 17(4), 689 (2004)

${ }^{10}$ L. Rogström, J. Ullbrand, J. Almer, L. Hultman, B. Jansson, and M. Odén, Thin Solid Films 520(17), 5542 (2012).

${ }^{11}$ B. Alling, A. V. Ruban, A. Karimi, O. E. Peil, S. I. Simak, L. Hultman, and I. A. Abrikosov, Phys. Rev. B 75, 045123 (2007).

${ }^{12}$ P. H. Mayrhofer, F. D. Fischer, H. J. Böhm, C. Mitterer, and J. M. Schneider, Acta Mater. 55, 1441 (2007).

${ }^{13}$ P. H. Mayrhofer, D. Music, and J. M. Schneider, Appl. Phys. Lett. 88, 071922 (2006).

${ }^{14}$ R. F. Zhang and S. Veprek, Mater. Sci. Eng., A 448(1-2), 111 (2007).

${ }^{15}$ A. Hörling, L. Hultman, M. Odén, J. Sjölén, and L. Karlsson, Surf. Coat. Technol. 191, 384 (2005).

${ }^{16}$ F. Tasnádi, I. A. Abrikosov, L. Rogström, J. Almer, M. P. Johansson, and M. Odén, Appl. Phys. Lett. 97, 231902 (2010).

${ }^{17}$ A. Knutsson, M. P. Johansson, L. Karlsson, and M. Odén, J. Appl. Phys. 108, 044312 (2010).

${ }^{18}$ R. Rachbauer, E. Stergar, S. Massl, M. Moser, and P. H. Mayrhofer, Scr. Mater. 61, 725 (2009).

${ }^{19}$ L. J. S. Johnson, M. Thuvander, K. Stiller, M. Odén, and L. Hultman, Thin Solid Films 520(13), 4362 (2012).

${ }^{20}$ R. Rachbauer, S. Massl, E. Stergar, P. Felfer, and P. H. Mayrhofer, Surf. Coat. Technol. 204(11), 1811 (2010).

${ }^{21}$ A. Hörling, "Thermal stability and age hardening of TiN-based thin films," Ph.D. dissertation (Linköping University, Sweden, 2005).

${ }^{22}$ R. Rachbauer, J. J. Genglerc, A. A. Voevodin, K. Resch, and P. H. Mayrhofer, Acta Mater. 60(5), 2091 (2012).

${ }^{23}$ M. Odén, L. Rogström, A. Knutsson, M. R. Terner, P. Hedström, J. Almer, and J. Ilavsky, Appl. Phys. Lett. 94, 053114 (2009).

${ }^{24}$ J. W. Cahn, Acta Metall. 14, 1685 (1966).

${ }^{25}$ J. W. Cahn and J. E. Hilliard, J. Chem. Phys. 28, 258 (1958).

${ }^{26}$ P. H. Leo and W. C. Johnson, Acta Mater. 49(10), 1771 (2001).

${ }^{27}$ T. J. Rappl and N. P. Balsara, J. Chem. Phys. 122, 214903 (2005).

${ }^{28}$ M. A. Davies, T. Ueda, R. M'Saoubi, B. Mullany, and A. L. Cooke, CIRP Ann. 56(2), 581 (2007).

${ }^{29}$ A. Knutsson, M. P. Johansson, L. Karlsson, and M. Oden, Surf. Coat. Technol. 205, 4005 (2011).

${ }^{30}$ J. Almer, U. Lienert, R. L. Peng, C. Schlauer, and M. Odén, J. Appl. Phys. 94(1), 697 (2003).

${ }^{31}$ P. R. Jemain, J. R. Weertman, G. G. Long, and R. D. Spal, Acta Metall. Mater. 39, 2477 (1991).

${ }^{32}$ J. Ilavsky, A. J. Allen, G. G. Long, and P. R. Jemian, Rev. Sci. Instrum. 73, 1660 (2002).

${ }^{33}$ J. Ilavsky and P. R. Jemian, J. Appl. Crystallogr. 42, 347 (2009).

${ }^{34}$ R. M. Langford and A. K. Petford-Long, J. Vac. Sci. Technol. A 19(5), 2186 (2001)

${ }^{35}$ J. W. Cahn, Acta Metall. 10, 789 (1962).

${ }^{36}$ B. Alling, A. V. Ruban, A. Karimi, L. Hultman, and I. A. Abrikosov, Phys. Rev. B 83, 104203 (2011).

${ }^{37}$ Flex PDE 6, V 6.16. PDE Solutions, Inc., 2011.

${ }^{38}$ R. Forsén, M. P. Johansson, N. Gahfoor, and M. Odén, J. Vac. Sci. Technol. A 30, 061506 (2012).

${ }^{39}$ U. Wahlström, L. Hultman, J. E. Sundgren, F. Adib, and I. Petrov, Thin Solid Films 235(62), 62 (1993).

${ }^{40}$ A. Knutsson, I. C. Schramm, K. Asp Grönhagen, F. Mücklich, and M. Odén, J. Appl. Phys. 113, 114305 (2013).

${ }^{41}$ S. Komura, Phys. Rev. B 31, 1278 (1985).

${ }^{42}$ J. W. Cahn, Acta Metall. 9(9), 795 (1961).

${ }^{43}$ A. Anders, Vacuum 67, 673 (2002).

${ }^{44}$ J. Almer, M. Odén, and G. Håkansson, Thin Solid Films 385, 190 (2001).

${ }^{45}$ N. Norrby, H. Lind, G. Parakhonskiy, M. P. Johansson, F. Tasnádi, L. S. Dubrovinsky, N. Dubrovinskaia, I. A. Abrikosov, and M. Odén, J. Appl. Phys. 113, 053515 (2013).

${ }^{46}$ M. W. Barsoum, Fundamentals of Ceramics (Taylor and Francis Group, New York, 2003). 